\title{
Exencephaly with Cystic Adenomatoid Malformation- A Review of a Rare Case
}

\author{
Nanda Patil ${ }^{1}$, Vaidehi Nagar ${ }^{2}$, Chirag Sharma ${ }^{3}$, Divya Brahmbhatt ${ }^{2}$ \\ ${ }^{1}$ Professor of Pathology, Krishna Institute of Medical Sciences Deemed to be University, Karad \\ ${ }^{2}$ Tutor of Pathology, Krishna Institute of Medical Sciences Deemed to be University, Karad \\ ${ }^{3}$ Tutor of Obstetrics and Gynaecology, Krishna Institute of Medical Sciences Deemed to be University, Karad \\ Corresponding Author: Vaidehi Nagar
}

\begin{abstract}
Exencephaly is a rare malformation of the cranium which is characterized by absence of skull, cranium cavity and a scalp with protruding brain tissue outside the skull. The prognosis for infants born with this malformation is extremely poor. Exencephaly has been associated with several other congenital anomalies. We present a case of exencephaly associated with cystic adenomatoid malformation in autopsy findings in a17weeks female abortus.
\end{abstract}

Key words: Exencephaly, acrania, cystic adenomatoid malformation

\section{INTRODUCTION}

Exencephaly is a rare type of cephalic disorder where the brain tissue is located outside the skull. Acraniaexencephaly-anencephaly sequence is the progression from relatively normal appearing brain tissue which is exposed outside the skull to an amorphous brain tissue to no recognisable brain tissue. This malformation is multifactorial in which both genetic as well as environmental factors play significant role ${ }^{(1)}$. We present a case of exencephaly in a 17 weeks female abortus with associated cystic adenomatoid malformation.

\section{CASE HISTORY}

A $35 y$ rs lady, $3^{\text {rd }}$ gravida presented with amenorrhea from 17 weeks. There was history consanguineous marriage. Antenatal ultrasonography report revealed absent cranial vault with maldeveloped brain tissue. The pregnancy was terminated and abortus was received for clinical autopsy.

\section{Autopsy findings}

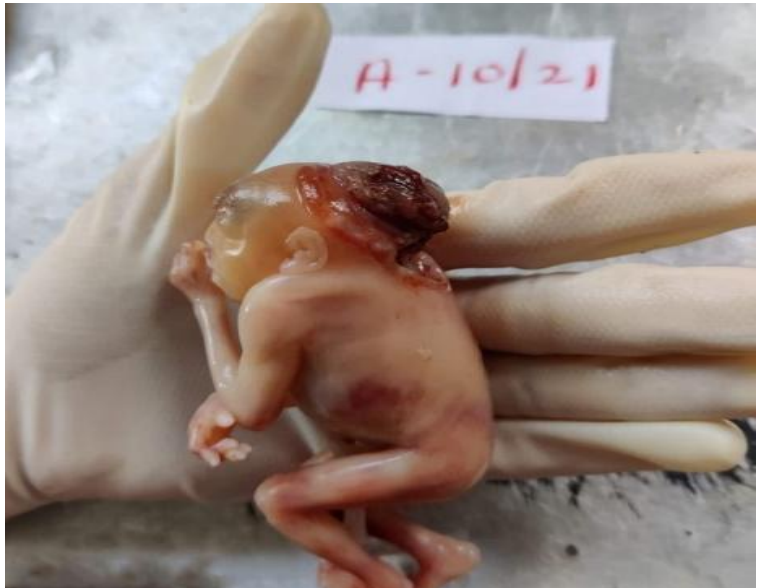

Fig 1: Absent cranial vault with protruding brain tissue, flat head

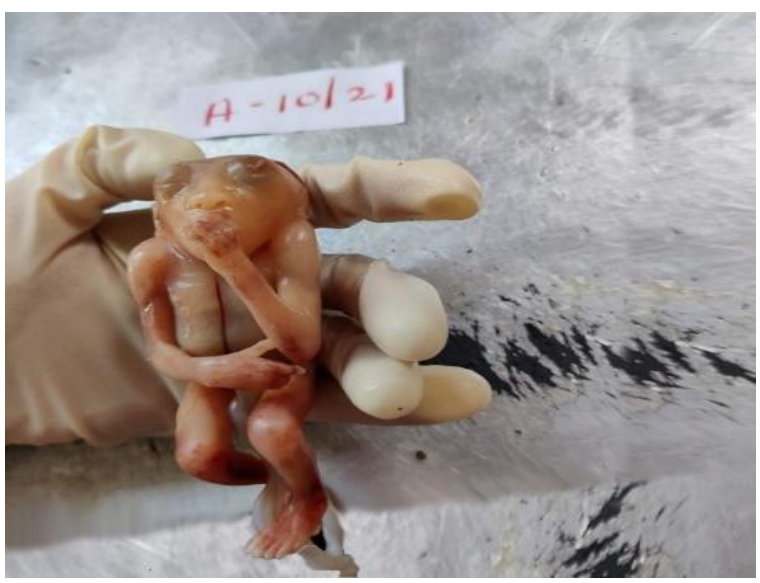

Fig 2: Prominent, budging eyrballs

A female abortus was received. On external examination revealed absent cranial vault with protruding brain tissue. The head 
was wide and irregularly shaped because of lack of calvarium. The head appeared flat (fig 1). The protruded brain tissue was soft and degenerated. The eyeballs were prominent and budging (Fig 2).

Microscopy of brain tissue revealed degenerating glial tissue. The layer between meninges and brain surface was composed of loose connective tissue with numerous tortuous vascular channels and focal nodules of dysplastic neural tissue (Fig3,4).
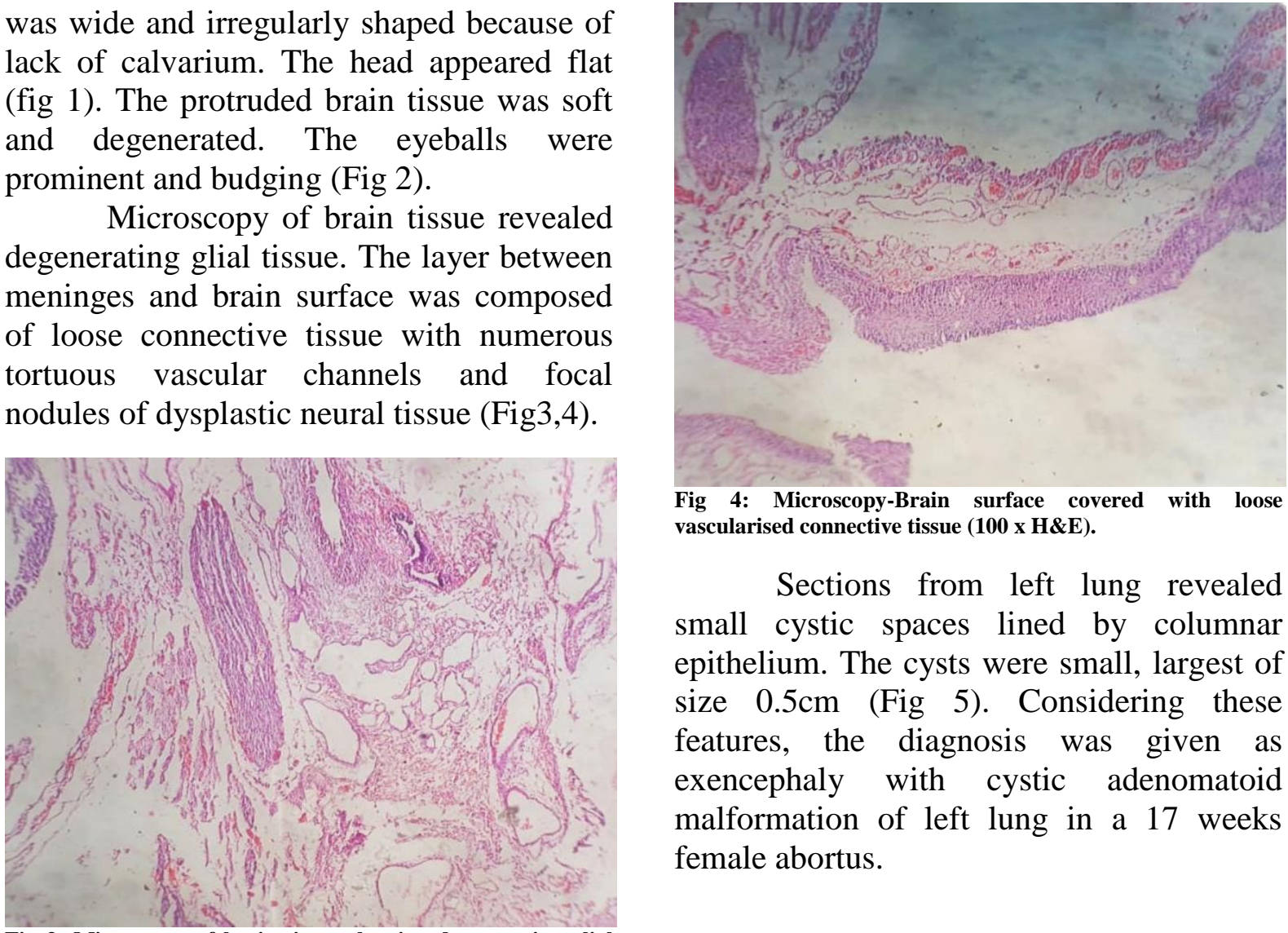

Fig 4: Microscopy-Brain surface covered with loose vascularised connective tissue ( $100 \times \mathrm{H} \& \mathrm{E})$.

Sections from left lung revealed small cystic spaces lined by columnar epithelium. The cysts were small, largest of size $0.5 \mathrm{~cm}$ (Fig 5). Considering these features, the diagnosis was given as exencephaly with cystic adenomatoid malformation of left lung in a 17 weeks female abortus.

Fig 3: Microscopy of brain tissue showing degenerating glial tissue (100x H\&E)
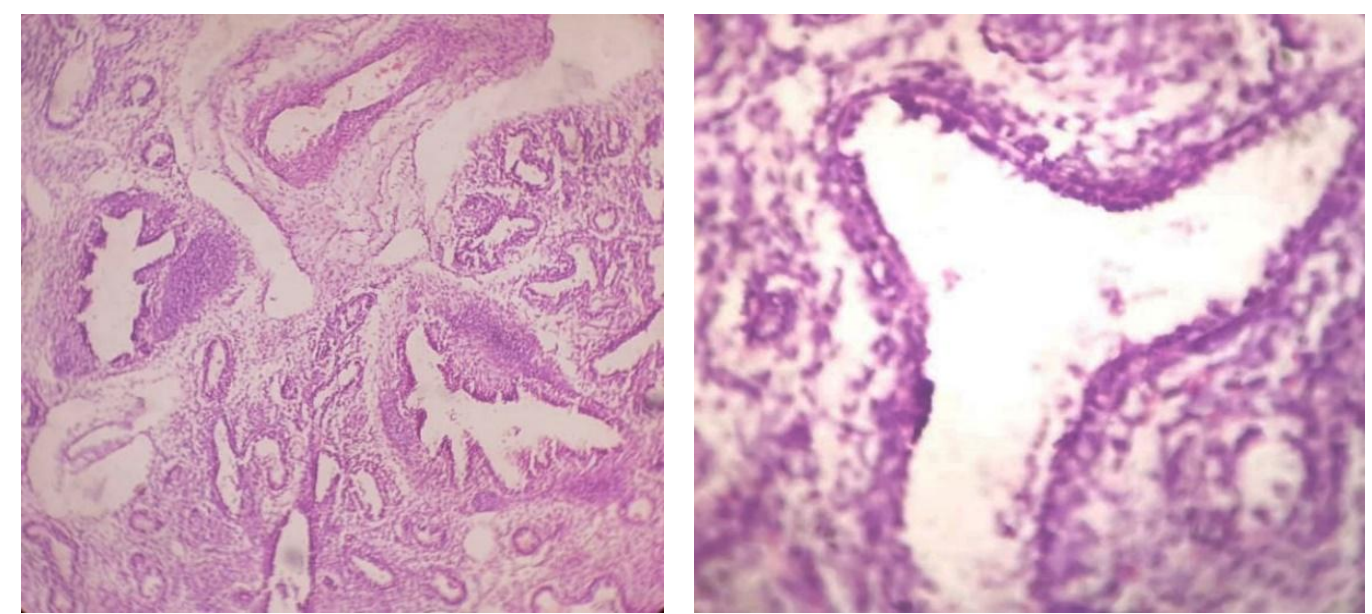

Fig 5: Microscopy of lung tissue (left lung) showing cystic spaces lined by cuboidal epithelium (100 x \& $400 \times \mathrm{H} \& \mathrm{E})$

\section{DISCUSSION}

Congenital defect of cranial vault refer to conditions with dismal prognosis. They include exencephaly, anencephaly, acalvaria and acrania ${ }^{(2)}$. Exencephaly has incidence of 3 cases per 10,000 pregnancies, with overall female preponderance ${ }^{(3)}$. Our case was also a female abortus. Exencephaly represents an embryonic precursor to anencephaly in which a brain tissue consists of a disorganised outgrowth of nervous tissue with polymicrogyria with absence of the calvaria. This disorganised brain tissue extends from a malformed skull base and is covered by only a vascular layer of epithelium, it degrades slowly by amniotic fluid and results into anencephaly $(4,5,6)$

In pathologic studies the exencephaly brain is covered by a highly 
vascular epithelial layer. Remaining central nervous system tissue is dysplastic with little or no neural differentiation ${ }^{(7)}$. Similar findings were noted in our case.

Exencephaly has been associated with severe congenital anomalies affecting multiple body systems. These are spina bifida, congenital heart defect, renal, skeletal and other anomalies ${ }^{(8)}$. Our case revealed a cystic adenomatoid malformation in left lung.

Diagnosis of exencephaly can often be done before birth through an ultrasonography examination between 14-18 weeks. The maternal serum alpha fetoprotein screening also helps in the diagnosis.

Prognosis of exencephaly is very poor. There is no cure or standard treatment. Most exencephalic fetuses do not survive birth accounting for $55 \%$ of non aborted cases. ${ }^{(9)}$

\section{CONCLUSION}

Exencephaly is a rare form of neural tube defect characterised by absence of cranial cavity and scalp with protruding brain.

The malformation is incompatible with life. Antenatal USG in first trimester helps in the diagnosis of this condition. Genetic counselling is recommended to decrease the risk of recurrence of neural tube defect.

Acknowledgement: None

Conflict of Interest: None

Source of Funding: None

\section{REFERENCES}

1. V. Renuka, R. Sasank, et al., "Exencephalyin a live, full term fetus," J. Pediatr. Neurosci., 2009, 4, (2),134-136.

2. C. Evans, T. Marton, et al, "Cranial vault defects: the description of three cases that illustrate a spectrum of anomalies," Pediatr. Dev. Pathol., 2009. 12, (2), 96-102.

3. Retrieved from https://en.wikipedia.org/ wiki/ Anencephaly.

4. Edwards L, Hui L. First and second trimester screening for fetal structural anomalies. Semin Fetal Neonat Med 2018; (23), 102-11.

5. Timor-Tritsch IE, Greenebaum E, et al., Exencephalyanencephal sequence: proof by ultrasound imaging and amniotic fluid cytology. J Matern Fetal Med 1996;(5),1825.

6. Deak KL, Siegel DG, George TM, et al. Further evidence for a maternal genetic effect and a sex-influenced effect contributing to risk for human neural tube defects. Birth Defects Res A Clin Mol Teratol 2008; 82:662-9.

7. Retrieved from http://obgyn.mhmedical.com/content. aspx ?bookid $=1306 \&$ sectionid $=75204588$.

8. Society for Maternal-Fetal Medicine, Monteagudo A. Exencephaly-anencephaly Sequence. Am J Obstet Gynecol. 2020 Dec; 223(6):B5-B8. doi: 10.1016/j.ajog. 2020. 08.176. Epub 2020 Nov 7. PMID: 33168213.

9. Retrieved from https://en.wikipedia.org/ wiki/Exencephaly.

How to cite this article: Patil N, Nagar V, Sharma $\mathrm{C}$ et.al. Exencephaly with cystic adenomatoid malformation-a review of a rare case. Gal Int J Health Sci Res. 2021; 6(2): 4547. DOI: https://doi.org/10.52403/gijhsr. 20210406 